\title{
Assessment of the Clinical Performance of Platelet Concentrates Treated by Pathogen Reduction Technology in Santiago de Compostela
}

\author{
M. Dolores Vilariño ${ }^{a} \quad$ Azucena Castrillo $^{b} \quad$ Alfredo Campos $^{a}$ Rachel Kilian $^{c}$ \\ Mercedes Villamayor ${ }^{a}$ Marcia Cardoso ${ }^{c}$ \\ a University Clinic of Santiago de Compostela, Santiago de Compostela, Spain; \\ ${ }^{b}$ Blood Transfusion Center of Galicia, Santiago de Compostela, Spain; \\ ${ }^{\mathrm{c}}$ Terumo BCT Europe, Zaventem, Belgium
}

\section{Keywords}

Riboflavin-based pathogen reduction .

Pathogen reduction . Clinical performance

\begin{abstract}
Summary
Introduction: This study assessed the feasibility, performance, and safety of Mirasol ${ }^{\circledR}$-treated platelet concentrates (M-PC) stored for up to 7 days. Methods: This prospective observational study was approved by the ethical committee of the University Clinic of Santiago de Compostela. Informed consent was asked from patients receiving M-PC. M-PCs were treated with the Mirasol system according to the manufacturer's instructions. Thrombocytopenic patients were transfused according to the Spanish transfusion guidelines. Post-transfusion platelet counts were measured at $1 \mathrm{~h}$ and/or $24 \mathrm{~h}$ after transfusion. Post-transfusion surveillance of patients was maintained during the study. Results: Data from 54 evaluable patients and 135 transfusions were analyzed. The mean age of patients was 58 years. The mean age of M-PC at transfusion was 3.6 days. The mean platelet dose was $3.7 \times 10^{11}$. The transfusion responses measured as mean corrected count increment $1 \mathrm{~h}$ after transfusion $\left(\mathrm{CCl}_{1 \mathrm{~h}}\right)$ and $\mathrm{CCl}_{24 \mathrm{~h}}$ were 9,659 and 4,751 , respectively. $65 \%$ of transfusions resulted in $\mathrm{CCl}_{1 \mathrm{~h}}$ values $\geq$ 7,500 . $51 \%$ of transfusions resulted in $\mathrm{CCl}_{24 \mathrm{~h}}$ values $\geq$ 4,500. Conclusion: The use of M-PC in the supportive treatment proved to be safe and effective for this cohort of thrombocytopenic patients.
\end{abstract}

C) 2016 S. Karger GmbH, Freiburg

\section{Introduction}

A safe and stable blood supply is paramount for a functional health system [1]. Regulatory agencies, blood providers and medical professionals are continuously implementing and improving measures that can guarantee a safe blood supply. Much of this effort was initiated in the face of emerging infectious threats in the blood supply, as exemplified by the experience with HIV. Despite the implementation of the HIV blood screening test, one of the most successful reactive safety measures ever implemented, society still had to pay a high price in terms of human lives and health as a result of not being prepared for the emergent pandemic of AIDS [2]. This experience only emphasized the fact that, although a zero risk for blood transfusion is unattainable [3], provision of the safest blood possible must remain one of the biggest commitments of world policy [4].

Modern times are characterized by intense world travel, migration, and increased global commercial interdependence (globalization). These factors add to demographic changes and contribute to the complexity of the task of maintaining safe blood [5]. Spain pioneered the use of pathogen reduction technology (PRT), initially for the treatment of fresh frozen plasma (FFP) [6]. The application of this proactive risk reduction measure was meant to contain the dissemination of infectious diseases in times of continuous threats, as seen with recent examples such as HIV/AIDS, severe acute respiratory syndrome (SARS), chikungunya and dengue outbreaks as well as West Nile virus infections.

The Blood Transfusion Center of Galicia supplies blood to 31 hospitals and a population of about 2.7 million inhabitants in the Northwestern region of Spain. It collects approximately 105,000 whole blood and 6,700 apheresis donations per year. Since 1998,

\section{KARGER}

(c) 2016 S. Karger GmbH, Freiburg 
Table 1. Patient groups transfused with M-PC during the observation period

\begin{tabular}{lcccccccc} 
& Total & $\begin{array}{l}\text { Acute } \\
\text { leukemia }\end{array}$ & NHL & HL & MDS & $\begin{array}{l}\text { Marrow } \\
\text { aplasia }\end{array}$ & $\begin{array}{c}\text { Multiple } \\
\text { myeloma }\end{array}$ & $\begin{array}{l}\text { Non-hematological } \\
\text { diseases }\end{array}$ \\
\hline Patients & 54 & 18 & 14 & 4 & 6 & 2 & 8 & 2 \\
\hline Transfusions & 135 & 59 & 29 & 10 & 15 & 6 & 11 & 5 \\
\hline
\end{tabular}

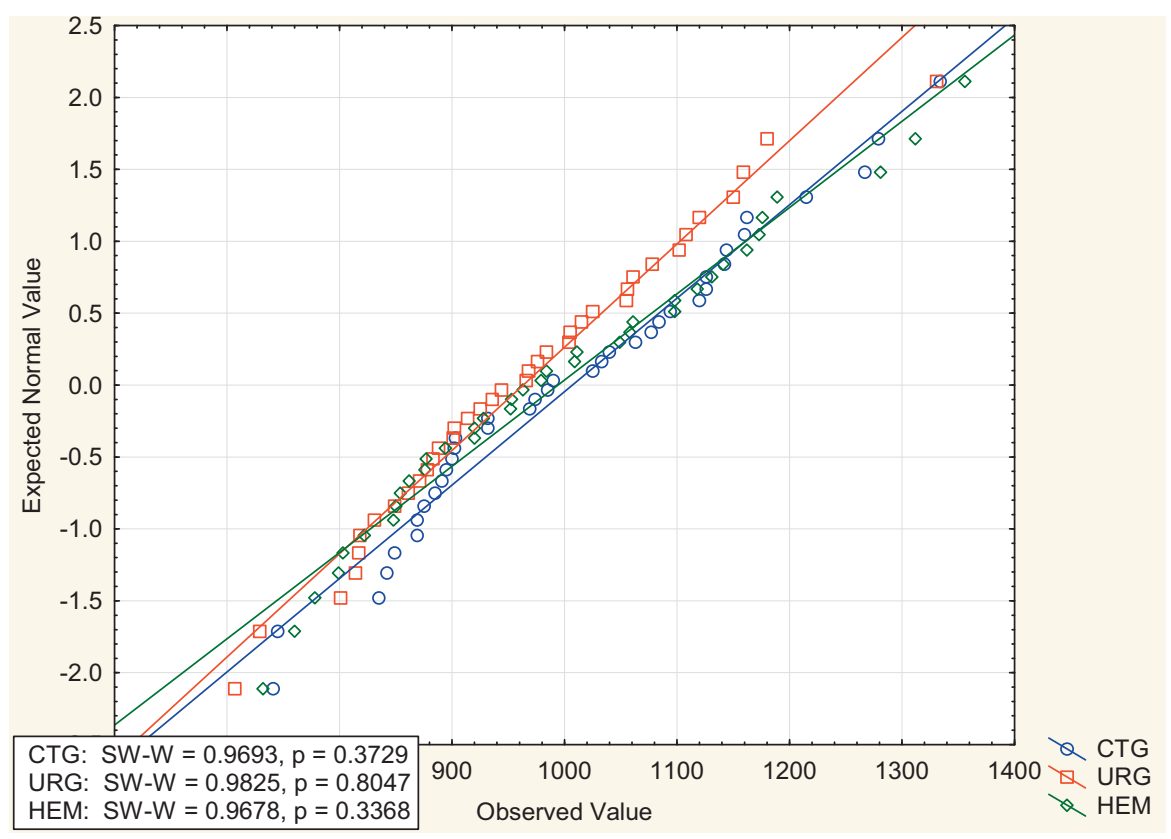

URG: $S W-W=0.98$ HEM: $S W-W=0.9678, p=0.3368$
Fig. 1. Statistical analysis to check equivalence of measurements by three different cell counters.
FFP has been treated with the Theraflex Methylene Blue system (MacoPharma, Langen, Germany) before transfusion. Platelet concentrates have been treated with the INTERCEPT PRT System (Cerus Corp, Concord, CA, USA) since 2008.

Recently, the Blood Transfusion Center of Galicia assessed the quality of Mirasol ${ }^{\circledR}$ PRT-treated (Terumo BCT, Lakewood, CO, USA) platelet concentrates (M-PC) and stored in platelet-additive solution for up to 7 days [7]. This technology uses riboflavin (vitamin $B_{2}$ ) and UV light to reduce the pathogen load and to inactivate contaminating white blood cells in blood components. Results of this study demonstrated acceptable platelet quality, which prompted the Blood Transfusion Center and the University Clinic of Santiago de Compostela to start a clinical study to investigate the performance of these products in the supportive therapy of thrombocytopenic patients. The study was designed to assess the feasibility, performance, and safety of M-PC stored for up to 7 days.

\section{Patients and Methods}

\section{Ethical Committee Approval and Patient Consent}

The protocol for a prospective observational study was submitted to the ethical committee of the University Clinic of Santiago de Compostela and granted approval before the start of the study. Patients receiving M-PC had to sign an informed consent form before starting therapy.
Preparation of Buffy Coat-Derived Platelet Concentrates and Mirasol PRT Treatment

Platelet concentrates processed from whole blood collections with the OrbiSac technology (Terumo BCT) were treated with the Mirasol PRT system according to the manufacturer's instructions for use. After treatment, M-PC were immediately released with no additional treatment. Platelets solved in the platelet-additive solution SSP+ (Macopharma) originated from 5 buffy coat pools and were stored up to 7 days at $22{ }^{\circ} \mathrm{C}$ on an agitator. Blood processing and treatment were done according to a protocol described in an earlier publication [7].

\section{Patients}

Exclusively stable thrombocytopenic patients were enrolled in this study. These patients were maintained on prophylactic platelet-supportive therapy according to the Spanish and international transfusion guidelines, as well as in accordance with the institution's standard practices. Only patients over the age of 18 receiving at least $1 \mathrm{U}$ of $\mathrm{M}-\mathrm{PC}$ were included in the study. Patients were excluded if they were refractory to platelet transfusion, if they showed active bleeding, if transfusion was needed during surgery, or if the informed consent form had not been signed. Patients received $\mathrm{ABO} / \mathrm{Rh}$ group-compatible platelets.

\section{Platelet Transfusions}

Post-transfusion platelet counts were measured at $1 \mathrm{~h}$ and/or $24 \mathrm{~h}$ after transfusion. Furthermore, post-transfusion surveillance of patients was maintained during the study period. All statistical analyses were conducted using SAS/BASE, SAS/STAT software, version 9.4 of the SAS System for Windows (SAS Institute Inc., Cary, NC, USA).

\section{Cell Counting}

Cell counters from three departments were used: Sysmex XT-20001 (Sysmex, Norderstedt, Germany) at the Blood Transfusion Center) COULTER AcT 


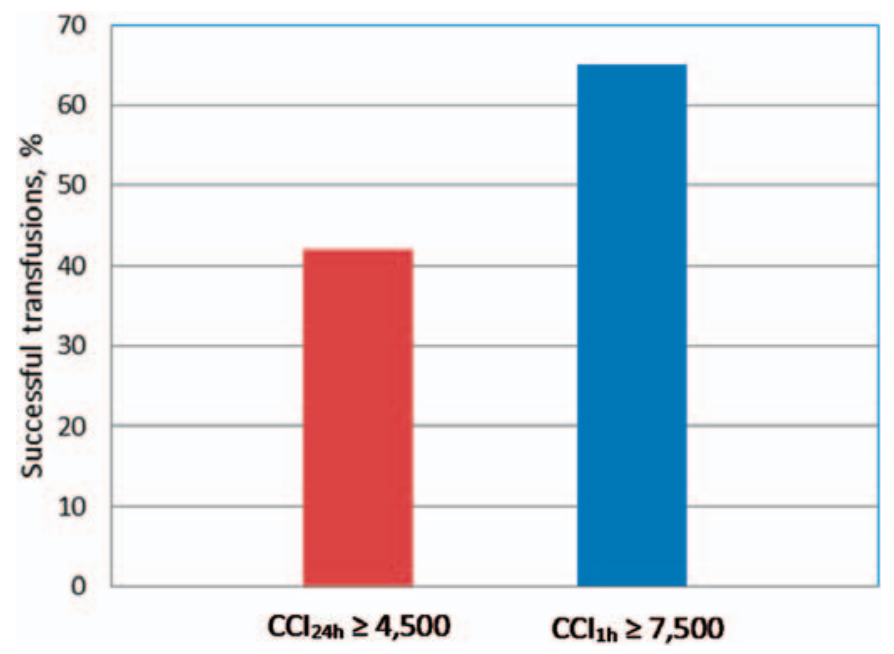

Fig. 2. Observed rates of successful transfusions, using thresholds of CCI1h $\geq 7,500$ and CCI24h $\geq 4,500$.

5 diff CP (Beckman Coulter Life Sciences, Indianapolis, IN, USA) at the emergency department, and Advia 2120i (Siemens Healthineers, Erlangen, Germany) at the hematology department. The Calibration of the three cell counters was performed by testing undiluted samples from the same platelet concentrate $(\mathrm{N}=38)$ prior to initiation of the study protocol. Statistical analyses were performed by means of Statsoft Inc. (2012) STATISTICA (data analysis software system), version 12 (Dell Statistica, Tulsa, OK, USA). Matrix plotting was used to assess the distribution and the regression for the various counter combinations. R-values all showed acceptable counter correlations.

\section{Platelet Performance Assessment}

Post-transfusion platelet counts were measured at $1 \mathrm{~h}$ and/or $24 \mathrm{~h}$ after transfusion. CI (count increment) and CCI (corrected count increment) were calculated using the following formulas (BSA = body surface area):

$\mathrm{CI}_{1 \mathrm{~h}}=(1$-hour post-transfusion platelet count $)-($ pre-transfusion platelet count) (1),

$\mathrm{CI}_{24 \mathrm{~h}}=$ (24-hour post-transfusion platelet count) - (pre-transfusion platelet count) (2),

$\mathrm{CCI}_{1 \mathrm{~h}}=\left(\mathrm{CI}_{1 \mathrm{~h}} /\right.$ transfused platelet dose $) \times \mathrm{BSA}$

$\mathrm{CCI}_{24 \mathrm{~h}}=\left(\mathrm{CI}_{24 \mathrm{~h}} /\right.$ transfused platelet dose $) \times \mathrm{BSA}$

$\mathrm{BSA}=0.0202457 \times$ height $^{0.725} \times$ weight $^{0.425}$

\section{Results}

\section{Platelet Concentrates Treated by Mirasol PRT}

The mean yield of transfused M-PC was $3.7 \times 10^{11}$, range $2.7-$ $5.0 \times 10^{11}$, standard deviation $(\mathrm{SD}) 0.5 \times 10^{11}$. The mean age of $\mathrm{M}-\mathrm{PC}$ at the time of transfusion was 3.6 days, range 2.7-5.0 days, SD 0.1 days. Nearly $90 \%(89.4 \%)$ of platelets were transfused at days $1-5$, the remaining $10.6 \%$ were transfused at days 6 and 7 .

\section{Patients}

55 patients were enrolled initially. One patient was excluded due to refractoriness. In total, transfusion data from 54 patients and 135 transfusions were analyzed. The mean age of patients was 58 years (range $32-82$ years). $55 \%$ of patients were male. Table 1 shows patients grouped by diagnosis: acute leukemia including

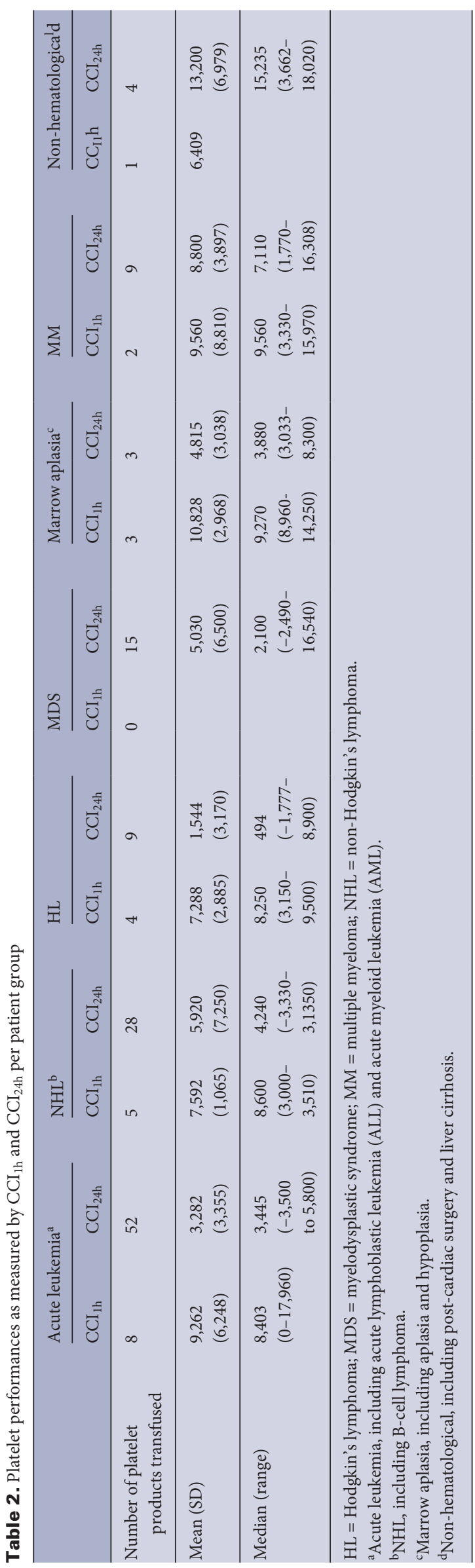


acute lymphoblastic leukemia (ALL) and acute myeloid leukemia (AML), non-Hodgkin's lymphoma (NHL) including B-cell lymphoma, Hodgkin's lymphoma (HL), myelodysplastic syndrome (MDS), marrow aplasia including aplasia and hypoplasia, and nonhematological diseases including post-cardiac surgery and liver cirrhosis. Clinical factors that led to increased platelet consumption were absent only in $32 \%$ of the enrolled patients. Most of the susceptible patients showed symptoms of fever and/or infection (24\%) or had recently undergone bone marrow transplantation (31\%).

\section{Calibration of Cell Counters}

Data measured from identical samples by the three different cell counters appeared to be normally distributed (Shapiro-Wilk; $\mathrm{p}>0.05$ for all), as demonstrated in figure 1 . The three populations measured on the three counters were found to be normally distributed (Shapiro-Wilk; $\mathrm{p}>0.05$ ). ANOVA revealed no difference between the counters $(p=0.4)$. Descriptive statistics, variability plotting, and box plotting showed similar population distributions for all counters. Hence, data collected by the counters could be used without any further calibration or extrapolation.

\section{Platelet Performance}

The mean number of transfusions per patient was 2.5, range 1-6, SD 1.5, median 2.0. Considered together, the observed mean of all transfusions $\mathrm{CCI}_{1 \mathrm{~h}}(\mathrm{n}=23)$, and $\mathrm{CCI}_{24 \mathrm{~h}}(\mathrm{n}=120)$ was 9,658 and 4,751 (table 2). $65 \%$ and $42 \%$ of transfusions showed CCI levels above the internationally accepted threshold for successful transfusions of 7,500 for $\mathrm{CCI}_{1 \mathrm{~h}}$ and 4,500 for $\mathrm{CCI}_{24 \mathrm{~h}}$ (fig. 2a). Based on the mean values of CCIs, transfusion responses were lower than thresholds in patients with acute leukemia $\left(\mathrm{CCI}_{24 \mathrm{~h}}\right)$ and $\mathrm{HL}$ $\left(\mathrm{CCI}_{24 \mathrm{~h}}\right)$ (fig. 2b).

Two acute transfusion reactions of grade I with imputability considered possible were observed during 135 transfusions.

\section{Discussion}

The Mirasol PRT technology was partially implemented at the Blood Transfusion Center of Galicia to guarantee the continuous supply of M-PC to the Department of Hematology and Hemotherapy of the University Clinic of Santiago de Compostela during the study period. Due to its simplicity, educating operators and implementing the technology went very smoothly, with treated products being released earlier than the ones treated with alternative technology employed at the site since 2008.

In this study, clinical performance of M-PC was evaluated by post-count increment determination after prophylactic transfusion of thrombocytopenic patients. Previous studies could show a clear relationship between transfusion failures, defined as increments below international recognized thresholds, and bleeding complications $[8,9]$. This study design was chosen to enable a performance as close as possible to the routine process at the hospital and also allow for comparative analysis with other routine experiences reported in the literature $[11,12]$. Thus, in this prospective study, count increment levels were used as markers of clinical performance. $\mathrm{CCI}_{1 \mathrm{~h}}$, a marker of platelet recovery, can be used as a surrogate for platelet quality; hence, results showing a rate of $65 \%$ effective transfusions in multiple transfused patients lie definitely within the expected levels of response and can confirm adequate platelet quality. This level of successful transfusions is slightly inferior to what has been reported by investigators in the Netherlands (72\%), equal to what has been recently observed in Switzerland (65\%) and superior to the reports from Norway (46\%). In all of these instances, platelets treated with an alternative pathogen reduction technology had been used [10-12]. Moreover, the observed rate is slightly inferior to what was observed in the MIRACLE study after transfusion of M-PC (71.3\%) [13].

$\mathrm{CCI}_{24 \mathrm{~h}}$ is a marker of survival and consequently very dependent on patient conditions. In view of the fact that $68 \%$ of the patients presented with platelet consumption factors at the time of transfusion, a successful response rate of $42 \%$ is quite acceptable. This patient variable becomes more evident if the clinical responses by patient group are analyzed (fig. 2b). Besides, the response rate observed in the present study was in the range observed in studies using alternative technologies, which range from $64 \%$ in the Dutch, $53 \%$ in the Norwegian and $28 \%$ in the Swiss reports. In the MIRACLE study, responses above the $\mathrm{CCI}_{24 \mathrm{~h}}$ threshold were observed in $51 \%$ of transfusions.

With regard to safety, two mild allergic reactions were recorded in 2 patients that were resolved without medication. These reactions were considered possibly related to the transfusion of the blood product, implying a rate of $1.5 \%$ for adverse events related to transfusion. This rate is far below the observed rate of $8 \%$ reported elsewhere for pathogen-inactivated platelet products treated with an alternative technology, and consistent with prior reports on M-PT $[11,14]$.

Altogether, the experience acquired in the processing of M-PT under 'routine-like' conditions and used in the supportive treatment of thrombocytopenic patients showed that the technology is easy to implement in the blood bank routine and that the treated platelet-containing products were safe and effective.

\section{Acknowledgement}

The authors want to thank Marc Antoon for the support with the statistical analysis used to check the calibration of the cell counters.

\section{Disclosure Statement}

Rachel Kilian and Marcia Cardoso are employees of Terumo BCT Europe. The other authors have no conflict of interest to disclose. 


\section{References}

1 Kralievits EK, Paylar NP, Greenberg SLM, Meara JG: The global blood supply: a literature review. Lancet 2015;285(suppl 2):28

2 Fauci AS: 25 years of HIV. Nature 2008;453:289-290.

3 Germain M, Ghibu S, Delage G: The precautionary principle in blood safety: not quite the same as aiming for zero risk. Transfus Med Rev 2012;26:181-184.

4 World Health Organization: Blood Safety and Availability. www.who.int/mediacentre/factsheets/fs279/en (last accessed October 7, 2016).

5 Morens DM, Fauci AS: Emerging infectious diseases: threats to human health and global stability. PLoS Pathog 2013;9:1-3.

6 Atance R, Pereira A, RamÍrez B: Transfusing methylene blue-photoinactivated plasma instead of FFP is associated with an increased demand for plasma and cryoprecipitate. Transfusion 2001;41:1548-1552.

7 Castrillo A, Cardoso M, Rouse L: Treatment of buffy coat platelets in platelet additive solution with the Mirasol ${ }^{\circledR}$ pathogen reduction technology system. Transfus Med Hemother 2013;40:44-48.
8 Schlichter SJ, Davis $\mathrm{K}$, Enright $\mathrm{H}$, Braine $\mathrm{H}$, Gernsheimer T, Kao KJ, Kickler T, Lee E, McFarland J, McCullough J, Rodey G, Schiffer CA, Woodson R: Factors affecting posttransfusion platelet increments, platelet refractoriness, and platelet transfusion intervals in thrombocytopenic patients. Blood 2005; 105:41064114.

9 Kerkhoffs JL, Einkenboom CJ, van de Watering LMG, van Wordragen-Vlaswinkel R, Wijermans PW, Brand A: The clinical impact of platelet refractoriness: correlation with bleeding and survival. Transfusion 2008;48: 1959-1965.

10 Kerkhoffs JLH, van Putten WLJ, Novitny VMJ, Te Boekhorst PAW, Schipperus MR, Zwaginga JJ, van Pampus LCM, de Greef GE, Luten M, Huijgens PC, Brand A, van Rhenen DJ: Clinical effectiveness of leucoreduced, pooled donor platelet concentrates, stored in plasma or additive solution with and without pathogen reduction. Br J Haematol 2010;150:209-217.
11 Sigle JP, Infanti L, Studt JD, Martinez M, Stern M, Gratwohl A, Passweg J, Tichelli A, Buser AS: Comparison of transfusion efficacy of amotosalen-based pathogen-reduced platelet components and gamma-irradiated platelet components. Transfusion 2013;53:17881797.

12 Apelseth TO, Bruserud $\varnothing$, Wentzel-Larsen T, Hervig $\mathrm{T}$ : Therapeutic efficacy of platelet transfusion in patients with acute leukemia: an evaluation of methods. Transfusion 2010;50:766-775.

13 Mirasol Clinical Evaluation Study Group: A randomized controlled clinical trial evaluating the performance and safety of platelets treated with MIRASOL pathogen reduction technology. Transfusion 2010;50: 2362-2375.

14 Łętowska M, Przybylska Z, Piotrowski D, Lachert E, Rzymkiewicz L, Cardoso M: Hemovigilance survey of pathogen-reduced blood components in the Warsaw region in the 2009 to 2013 period. Transfusion 2016; 56(suppl 1):39-44. 